\title{
Correlations between island (in)sensitivity and base positions of (non-)standard $w h$-in-situ
}

\author{
Okgi Kim \& Seulkee Park*
}

\begin{abstract}
It has been well-accepted in the literature that the island (in)sensitivity of $w h$-in-situ falls under the so-called Noun versus Adverb Generalization (NAG), which states that an in-situ $w h$-phrase is island-free iff it is (or contains) a $w h$ nominal (Tsai 1994a,b; Stepanov \& Tsai 2008; Fujii et al. 2014). However, we show that the NAG is not sufficient to explain the island behaviors of some (non)standard in-situ wh-phrases in Korean. Alternatively, we suggest that the island (in)sensitivity of in-situ wh-phrases may correlate not with their categorial status but with their base-generated positions: specifically, we assume that an in-situ whphrase that is base-generated in the $\mathrm{CP}$ domain (Spec-CP) is island-sensitive, while an in-situ $w h$-phrase that is base-generated below CP/TP is island-insensitive.
\end{abstract}

Keywords. (non-)standard $w h$-in-situ; island sensitivity; base position; Noun versus Adverb Generalization

1. Asymmetries in island effects. Since Huang (1982a,b), it has been well-known that wh-insitu languages exhibit an argument-adjunct asymmetry with respect to island sensitivity. For an illustration, consider the case of a complex NP island in Chinese and Korean:
a. ni zui xihuan [NP [CP mai shenme] de ren]? you most like buy what DE person
(Chinese) 'What do you like the person who bought $t$ ?'

b. *ni zui xinshang [NP [CP weishenme gongzuo] de ren]? you most appreciate why work DE person 'What is the reason $\mathrm{x}$ such that you appreciate most people who work for $\mathrm{x}$ ?' (Stepanov and Tsai 2008: (9b))
a. Mimi-nun [NP [CP mwe-l kkay-n] salam]-ul pinanhayss-ni?
Mimi-TOP what-ACC break-MOD person-ACC criticized-QUE
'Mimi criticized the person who broke what?'
b. *Mimi-nun [NP [CP way kkochpyeng-ul kkay-n] salam]-ul pinanhayss-ni? Mimi-TOP why vase-ACC break-MOD person-ACC criticized-QUE 'Mimi criticized the person who broke the vase why?'

In both the Chinese and Korean examples, the wh-arguments-shenme in (1a) and mwe-l in (2a) — can occur inside the complex NP island, whereas the reason wh-adjuncts-weishenme in (1b) and way in (2b) - cannot. ${ }^{1}$

To account for such asymmetries in island effects, many researchers (e.g., Tsai 1994a,b; Stepanov \& Tsai 2008; Fujii et al. 2014) have argued, under an unselective-binding approach, that the island behaviors of $w h$-in-situ fall under the morphological generalization in (3), which, following Fujii et al. (2014), we refer to as the Noun versus Adverb Generalization. ${ }^{2}$

\footnotetext{
* Authors: Okgi Kim, University of Wisconsin-Milwaukee (okgikim@uwm.edu) \& Seulkee Park, Kyung Hee University (seulkeepark@khu.ac.kr).

${ }^{1}$ The form mwe-l is a contracted form of mwues-ul.

${ }^{2} \mathrm{~A}$ wh-nominal that introduces a choice function variable can be licensed inside an island by a Q-operator via unselective binding, as illustrated in (ia). On the other hand, a wh-adverb is not licensed in-situ, since it does not
} 


\section{(3) Noun versus Adverb Generalization (NAG):}

An in-situ $w h$-phrase is island-insensitive iff it is (or contains) a wh-nominal. (Fujii et al. 2014: (3))

The NAG gives a straightforward account of the contrasts in (1) and (2): the $w h$-arguments shenme and mwe-l are island-insensitive since they are $w h$-nominals, whereas the reason $w h$ adjuncts weishenme and way are island-sensitive since they are pure wh-adverbs.

2. Counterexamples to the NAG. Here we show that island (in)sensitivity of in-situ $w h$-phrases in Korean is not properly constrained by the NAG. Before we proceed, however, we would like to briefly introduce two different but similar types of non-standard wh-question in Korean, whose island behaviors, as we will see, play a key role in testing whether the NAG is empirically correct or not. Consider (4) and (5).
a. Mimi-nun mwe-lw kulehkey manhun nonmwun-ul ilkess-ni?
Mimi-TOP what-ACC so many paper-ACC read-QUE
'Why did Mimi read so many papers?'
b. Mimi-nun mwe-l ilkess-ni?
Mimi-TOP what-ACC read-QUE
'What did Mimi read?'

a. John-un ettehkey ${ }^{\mathrm{w}}$ hankwuk-ey ka-key toyess-ni?

John-TOP how South.Korea-to go-CONN became-QUE

'Why did John go to South Korea?'

b. John-un ettehkey kkochpyeng-ul kkayss-ni?

John-TOP how vase-ACC broke-QUE

'How did John break the vase?'

The $w h$-questions like (4a) and (5a) are taken to be non-standard wh-questions in the sense that a non-'why' wh-phrase receives a 'why'-like interpretation. In (4a), the wh-phrase $m w e-l$, which canonically functions as an argument in a sentence as in (4b), behaves like a $w h$-adjunct corresponding to way 'why'. In a similar manner, in (5a), the wh-phrase ettehkey, which is standardly used as a manner or instrumental adjunct as in (5b), is interpreted as a reason $w h$ adverbial when it occurs with a causative -key toy-construction with past tense. ${ }^{3}$ As indicated in (4a) and (5a), throughout the paper, the superscript ${ }^{\mathrm{w}}$ is used in glossing the non-standard $w h$-items (i.e., reason mwe-l and reason ettehkey) and distinguishing them from their standard counterparts ( $w h$-argument $m w e-l$ and manner/instrumental ettehkey).

Now let us examine whether or not the NAG correctly predicts island (in)sensitivity of

introduce a variable subject to unselective binding and, therefore, relies on local binding with subsequent covert movement to its scope position, in which case it induces island effects when it occurs inside an island, as illustrated in (ib). See Tsai (1994a) and Stepanov \& Tsai (2008) for detailed discussion of unselective binding.

unselective binding

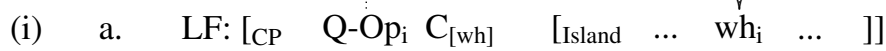
covert movement

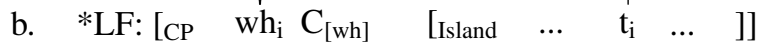

${ }^{3}$ See Yeo (2019) for discussion of causative -key toy-constructions. 
(non-)standard $w h$-in-situ in Korean. If the NAG is on the right track, then it is expected that manner/instrumental ettehkey is island-sensitive, since it is a wh-adverb; however, as shown in (6), it is island-insensitive in that it can occur inside a complex NP island or an adjunct island (Chung 2000, 2005).
a. Mimi-nun [NP [CP Kim-i ettehkey yoliha-n] umsik]-ul mekess-ni?
Mimi-TOP Kim-NOM how cook-MOD food-ACC ate-QUE
'Mimi ate the food that Kim cooked how?'
b. Mimi-nun [ст Kim-i ettehkey umsik-ul yolihay-se] hwakanass-ni?
Mimi-TOP Kim-NOM how food-ACC cook-because got.upset-QUE
'Mimi got upset because Kim cooked the food how?'

In dealing with the island insensitivity of manner/instrumental ettehkey, Chung (2005) offers an interesting proposal under an unselective-binding approach. On his view, manner/instrumental ettehkey can be decomposed into four sub-parts, [DP/NP $e$-tte]-h-key 'Det-CNP-do-adverbializer': the first part $e$ is a determiner which combines with the common noun phrase tte that follows it, the third part $h(a)$ is a transitive verb that takes the preceding DP/NP, and the final part key is an adverbializer. Based on this morphological structure, Chung explains that the insensitivity of manner/instrumental ettehkey to strong islands is because it contains the nominal element tte that introduces a variable subject to unselective binding: that is, its island behavior is captured by the NAG. If Chung's nominal analysis is on the right track, then it is expected that reason ettehkey is island-insensitive, since its morphological form is the same as its standard counterpart; however, that is not the case, as evidenced by the ungrammatical examples in (7) where reason ettehkey cannot occur inside a complex NP island and an adjunct island, just like way.
a.
Mimi-TOP
mekess-ni?
*Mimi-nun [NP [CP Kim-i
Kim-NOM how/why
$\left\{\right.$ ettehkey $\left.^{\mathbf{w}} / \mathbf{w a y}\right\}$ yoliha-key toy-n]
umsik]-ul
ate-QUE
'Mimi ate the food that Kim cooked why?'
b. *Mimi-nun [CP Kim-i \{ ettehkey $\left.^{\mathbf{w}} / \mathbf{w a y}\right\}$ umsik-ul yoliha-key toy-se]
Mimi-TOP Kim-NOM how/why food-ACC cook-CONN become-because
hwakanass-ni?
got.upset-QUE
'Mimi got upset because Kim cooked the food why?'

Contra Chung's proposal, although we treat both manner/instrumental and reason ettehkey as pure $w h$-adverbs, the NAG still has difficulty accounting for the asymmetry between the two variants of ettehkey in island contexts: since the two variants are $w h$-adverbs, they both must be island-sensitive according to the NAG, contrary to fact.

The NAG may also have difficulty explaining the asymmetry between reason $m w e-l$ and its standard counterpart (i.e., wh-argument) in island effects. Under the NAG, reason $m w e-l$ is predicted to be island-insensitive, since it is a wh-nominal; however, the prediction is not borne out, as seen in (8) where reason $m w e-l$ is sensitive to a complex NP island, as in (8a), and an adjunct island, as in $(8 \mathrm{~b})$.
a. *Mimi-nun $[\mathrm{NP}[\mathrm{CP}$ Mimi-TOP
$\{$ mwe-lw/way kulehke what-ACC/why so
many
nonmwun-ul ilk-un]
paper-ACC read-MOD 
salam]-ul pinanhayss-ni?

person-ACC criticized-QUE

'Mimi criticized the person who read so many papers why?'

b. *Mimi-nun [CP Kim-i $\left\{\right.$ mwe-I $\left.{ }^{\mathbf{w}} / \mathbf{w a y}\right\}$ kulehkey ilccik ttena-se]

Mimi-TOP Kim-NOM what-ACC/why so ealy leave-because

hwakanass-ni?

got.upset-QUE

'Mimi got upset because Kim left so early why?'

\section{Correlations between island (in)sensitivity and base positions of (non-)standard $w h$-in-situ.}

In the previous section we have demonstrated that the NAG fails to capture the island (in)sensitivity of some (non-)standard in-situ wh-phrases in Korean. Here, as an attempt to provide a (potential) alternative view to the NAG, we suggest that island (in)sensitivity of in-situ wh-phrases may correlate with their base-generated positions, not with their categorial status (i.e., noun versus adverb), by showing that an in-situ wh-phrase base-generated in the CP domain (Spec$\mathrm{CP}$ ) is island-sensitive, while an in-situ wh-phrase base-generated below CP/TP is island-insensitive.

\subsection{TWO DIAGNOSTIC TESTS FOR IDENTIFYING $w h$-PHRASES BASE-GENERATED IN THE CP} DOMAIN. Korean is well-known as exhibiting an asymmetry between way 'why' and other whoperators with respect to the Intervention Effect: unlike the latter, the former does not exhibit the Intervention Effect when c-commanded by a Scope Bearing Element (SBE) like amwuto 'anyone' or man 'only' (Beck \& Kim 1997; Beck 2006; Ko 2005, 2006). ${ }^{4}$ Consider (9).

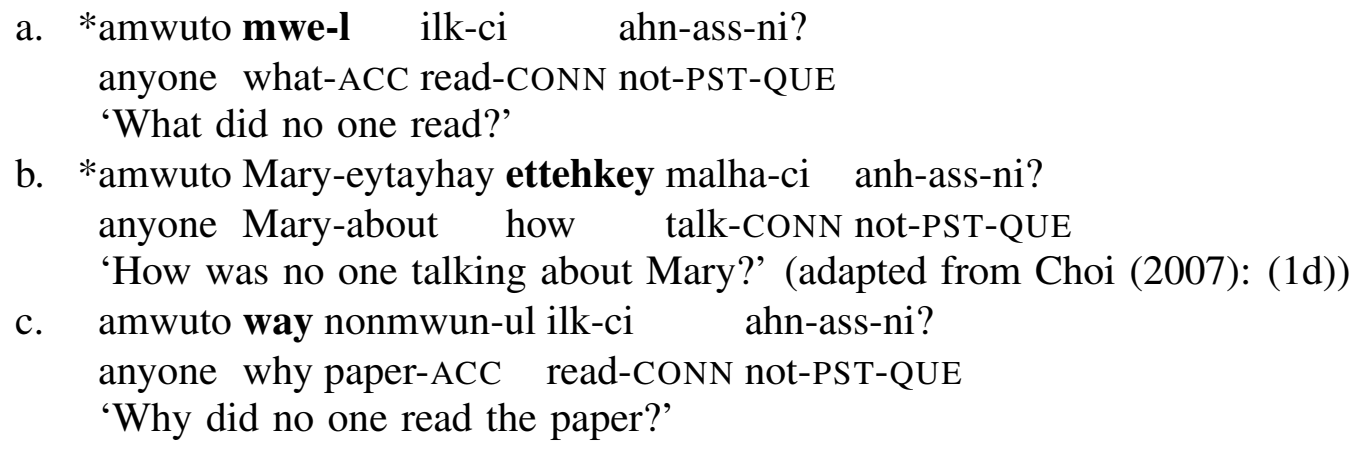

As illustrated here, unlike the wh-argument mwe-l and the manner/instrumental ettehkey, the wh-adjunct way can follow the SBE amwuto.

To account for the peculiar behavior of way in terms of the Intervention Effect, i.e., its ability to be preceded by an SBE, Ko (2005) assumes that way in an interrogative clause is externally merged in its checking position, Spec-CP (CP-Modifier Hypothesis), while other whphrases undergo LF movement to Spec-CP for feature checking. This is illustrated in (10).

$$
\begin{aligned}
& \text { a. [CP way } \mathrm{C}_{[+\mathrm{Q}]}\left[\begin{array}{lll}
\mathrm{II} & \ldots &
\end{array}\right]
\end{aligned}
$$

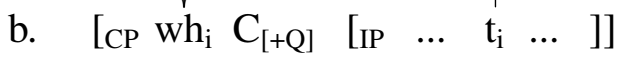

In addition, she proposes the Intervention Effect Constraint, where at LF a wh-phrase cannot move across an SBE to its checking (scope) position, as illustrated in (11) (cf. Beck and Kim 1997).

${ }^{4}$ SBEs also include anh 'not', pakkey 'only' (NPI), to 'also', nwukwunka '(non-specific) someone', and nwukwuna 'everyone'. See Ko (2005) for relevant examples. 


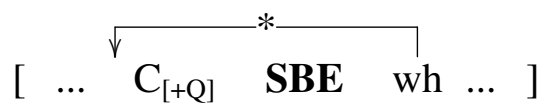

On Ko's analysis, the ungrammaticality of (9a) and (9b) is simply because the SBE amwuto blocks LF movement of the given $w h$-phrase to Spec-CP, as illustrated in (12).

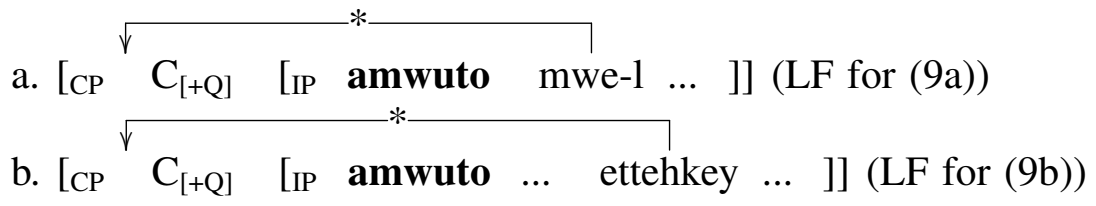

Meantime, the well-formedness of $(9 \mathrm{c})$ is because the wh-adjunct way is licensed in its base position (i.e., Spec-CP) and, therefore, does not move across the c-commanding SBE which has undergone overt scrambling over the $w h$-phrase:

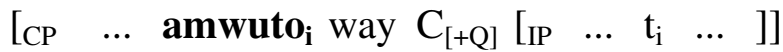

As noted by Ko (2005), the external merge of way at Spec-CP is supported by the fact that it always takes wide scope over negation in an interrogative clause:

(14) John-un way Mary-lul cohaha-ci-anh-ni?

John-TOP why Mary-ACC like-CI-not-QUE

'What is the reason $\mathrm{x}$ such that John does not like Mary? (Reason $\gg$ Not)'

'*What is not the reason $\mathrm{x}$ such that John likes Mary for $\mathrm{x}$ ? (Reason $\ll$ Not)'

(Ko 2005: (55))

Since the reason wh-adjunct way is base-generated in the CP domain, it is impossible for it to be interpreted under the negation in IP.

Adopting Ko's ideas, we assume that if a $w h$-phrase (i) does not show the Intervention Effect when c-commanded by an SBE in an interrogative clause and (ii) takes obligatory wide scope over negation, then it is taken to be base-generated in the CP domain (Spec-CP).

3.2. EXTERNAL MERGE OF NON-STANDARD $w h$-IN-SITU IN THE CP DOMAIN. Reason $m w e-l$ is assumed to originate in the $\mathrm{CP}$ domain given that, like way, it can be preceded by an SBE, as in (15a), and takes wide scope over negation in an interrogative clause, as in (15b).

(15) a. Mimi-man $\{$ mwe-Iw/way $\}$ kulehkey manhun nonmwun-ul ilkess-ni?

Mimi-only what-ACC/why so many paper-ACC read-QUE

'Why did only Mimi read so many papers?'

b. John-un $\{$ mwe-1w/way $\}$ kulehkey swipkey cichi-cito anh-ni?

John-TOP what-ACC/why so easily get.tired-CONN not-QUE

'What is the reason $x$ such that John does not get tired so easily (Reason $\gg$ Not)'

'*What is not the reason $\mathrm{x}$ such that John gets tired so easily for $\mathrm{x}$ ?

(Reason $\ll$ Not)'

Reason ettehkey also behaves like way in regard to the Intervention Effect and scopal interactions with negation, as illustrated in (16), indicating that it is base-generated in the $\mathrm{CP}$ domain.

a. amwuto ettehkey ${ }^{\mathrm{w}} /$ way nonmwun-ul ilk-ci anh-key toyess-ni?

anyone how/why paper-ACC read-CONN not-CONN became-QUE

'Why didn't anyone read papers?' 
b. John-un ettehkey ${ }^{\mathbf{w}} / \mathbf{w a y}$ hankwuk-ey ka-ci anh-key toyess-ni?

John-TOP how/why South.Korea-to go-CONN not-CONN became-QUE

'What is the reason $x$ such that John didn't go to South Korea? (Reason $\gg$ Not)'

'*What is not the reason $\mathrm{x}$ such that John went to South Korea for $\mathrm{x}$ ?

(Reason $\ll$ Not)'

Meantime, manner/instrumental ettehkey is assumed to be base-generated below NegP (in IP) in that it is subject to the Negative Island Effect, where negation blocks extraction of certain (wh-)phrases (Rizzi 1990; Tsai 2008; Shlonsky \& Soare 2011). Consider the contrast in (17).
a. Mimi-nun way cha-lul kochi-ci ahn-ass-ni?
Mimi-TOP why car-ACC fix-CONN not-PST-QUE
'Why didn't Mimi fix the car?'
b. *Mimi-nun ettehkey cha-lul kochi-ci ahn-ass-ni?
Mimi-TOP how car-ACC fix-CONN not-PST-QUE
'How didn't Mimi fix the car?'

As observed in (17a), the reason wh-adjunct way is not sensitive to negation in the clause with which it is construed. This can be explained by Ko's (2005) analysis that assumes that way is base-generated in the $\mathrm{CP}$ domain (above NegP). On the other hand, the ungrammaticality of (17b) can be accounted for by assuming that manner/instrumental ettehkey originates in a structurally lower position below negation and that its LF movement to Spec-CP is blocked by the negator, inducing the Negative Island Effect. Notice that, as can be seen in (16), reason ettehkey is exempt from the Negative Island Effect, just like way, which supports the claim that reason ettehkey is base-generated in the $\mathrm{CP}$ domain.

3.3. ISLAND-SENSITIVE, NON-STANDARD $w h$-IN-SITU. Taken together, we have seen that the non-standard in-situ wh-phrases, which are base-generated in the CP domain (Spec-CP), are island-sensitive (see (7) and (8)), while their standard counterparts (wh-argument and manner/ instrumental $w h$-adjunct), which are base-generated below CP/TP, are island-insensitive (see (2a) and (6)).

3.4. ISLAND (IN)SENSITIVITY AND BASE POSITIONS OF OTHER IN-SITU $w h$-PHRASES. The other in-situ $w h$-phrases that we have not examined so far, such as $n w u k w u$ 'who' and 'low' $w h$-adjuncts like encey 'when' and eti 'where', are all island-insensitive. For instance, examples in (18) show that they are insensitive to a complex NP island.
a. John-un [NP [CP nwu-ka yoriha-n] umsik-ul] mek-ess-ni? John-TOP who-NOM cook-MOD food-ACC eat-PST-QUE 'John ate the food that who cooked?'
b. John-un [NP [CP Mimi-ka encey yoriha-n] umsik-ul] mek-ess-ni? John-TOP Mimi-NOM when cook-MOD food-ACC eat-PST-QUE 'John ate the food that Mimi cooked when?'
c. John-un [NP [CP Mimi-ka eti-se yoriha-n] umsik-ul] mek-ess-ni? John-TOP Mimi-NOM where-LOC cook-MOD food-ACC eat-PST-QUE 'John ate the food that Mimi cooked where?'

All these island-insensitive $w h$-phrases presented here are known as being base-generated below CP/TP. This is consistent with the proposed view that an in-situ wh-phrase is island-sensitive 
iff it is base-generated in the CP domain.

4. Summary. The correlations between island (in)sensitivity and base positions of (non-)standard in-situ wh-phrases in Korean we have examined so far are summarized in Table 1.

\begin{tabular}{|c|c|c|c|c|}
\hline & wh-phrases & categories & island (in)sensitivity & base positions \\
\hline \multirow{5}{*}{ standard } & $m w e-l / m w u e s-u l$ 'what' & $\mathrm{NP}$ & insensitive & below CP/TP \\
& $n w w k w u$ 'who' & $\mathrm{NP}$ & insensitive & below CP/TP \\
& ettehkey 'how' & $\mathrm{AdvP}$ & insensitive & below CP/TP \\
& $e n c e y$ 'when' & $\mathrm{NP} / \mathrm{PP}$ & insensitive & below CP/TP \\
& eti 'where' & $\mathrm{NP} / \mathrm{PP}$ & insensitive & below CP/TP \\
& way 'why' & $\mathrm{AdvP}$ & sensitive & in the CP domain \\
\hline \multirow{2}{*}{ non-standard } & reason $m w e-l$ & $\mathrm{NP}$ & sensitive & in the CP domain \\
& reason ettehkey & $\mathrm{AdvP}$ & sensitive & in the CP domain \\
\hline
\end{tabular}

Table 1. Correlations between island (in)sensitivity and base positions of (non-)standard in-situ wh-phrases in Korean

The table shows that an in-situ wh-phrase base-generated below CP/TP is island-insensitive, whereas an in-situ wh-phrase base-generated in the CP domain (Spec-CP) is island-sensitive, regardless of whether the given $w h$-phrase is a $w h$-nominal (e.g., reason $m w e-l$ ) or a $w h$-adverb (e.g., manner/instrumental ettehkey), a standard wh-phrase or a non-standard wh-phrase. ${ }^{5}$

5. How about other $\boldsymbol{w h}$-in-situ languages?. Our preliminary literature review, which is summarized in Table 2, indicates that the proposed correlation between island (in)sensitivity and base positions of wh-in-situ may also hold for Chinese and Japanese.

\begin{tabular}{|c|c|c|c|c|}
\hline Ig. & wh-phrases & island (in)sensitivity & base positions & references \\
\hline \multirow{4}{*}{ Chinese } & reason weishenme 'why' & sensitive & in the CP domain & Lin 1992, Ko 2005 \\
\cline { 2 - 5 } & purpose wei(-le) shenme 'for what' & insensitive & below CP/TP & Stepanov \& Tsai 2008 \\
\cline { 2 - 5 } & causal zenme 'how' & sensitive & in the CP domain & Tsai 2008, Jin 2016 \\
\cline { 2 - 5 } & manner zenme 'how' & insensitive & below CP/TP & Jin 2016, Murphy 2017 \\
\cline { 2 - 5 } ('who', 'what', 'when', 'where') & insensitive & below CP/TP & \\
\cline { 2 - 5 } Japanese & $\begin{array}{c}\text { other whs 'why' } \\
\text { 'fonna riyuu-des }\end{array}$ & sensitive & in the CP domain & Ko 2005, (Ochi 2014) \\
\cline { 2 - 5 } & $\begin{array}{c}\text { doo (yatte) 'how' } \\
\text { other whs }\end{array}$ & insensitive & below CP/TP & Ko 2005, Fujii et al. 2014 \\
\cline { 2 - 5 } & $\begin{array}{c}\text { insensitive } \\
\text { ('who', 'what', 'when', 'where') }\end{array}$ & insensitive & below CP/TP & Fujii \& Takita 2007 \\
\hline
\end{tabular}

Table 2. Correlations between island (in)sensitivity and base positions of $w h$-in-situ in Chinese and Japanese

\footnotetext{
${ }^{5}$ In a similar vein, Murphy (2017) proposes that island sensitivity of in-situ $w h$-adverbs correlates with their adjunction height: that is, $v \mathrm{P}$-adjuncts are island-insensitive, while TP-adjuncts are island-sensitive. This proposal is based on an operator binding approach. See Murphy (2017) for detail discussion.
} 
6. Concluding remarks and further work. In this paper we have demonstrated that the NAGthe well-accepted generalization in accounting for island (in)sensitivity of $w h$-in-situ-is not enough to capture the island behaviors of some (non-)standard in-situ wh-phrases in Korean. Alternatively, we have suggested that the island (in)sensitivity of (non-)standard in-situ whphrases may correlate with their base positions, by showing that an in-situ wh-phrase is islandsensitive iff it is base-generated in the $\mathrm{CP}$ domain. However, there remain many important issues to be addressed to confirm the crosslinguistic validity of the generalization and to explain the resulting pattern. We need to do further work to see whether the proposed correlation is applicable over a wide range of $w h$-in-situ languages and to provide theoretical support. Although we leave the crucial issues unresolved here, we hope the (potential) proposed correlation between island (in)sensitivity and base positions gives researchers new insights into understanding various asymmetries in island effects in $w h$-in-situ languages.

\section{References}

Beck, Sigrid, \& Shin-Sook Kim. 1997. On wh-and operator scope in Korean. Journal of East Asian Linguistics 6(4). https://doi.org/10.1023/A:1008280026102.

Beck, Sigrid. 2006. Intervention effects follow from focus interpretation. Natural Language Semantics 14(1). 1-56. https://doi.org/10.1007/s11050-005-4532-y.

Chung, Daeho. 2000. On the Licensing of HOW. Studies in Generative Grammar 9(2). 337360.

Chung, Daeho. 2005. Why is HOW in Korean insensitive to islands?: A revised nominal analysis. Studies in Modern Grammar 39. 115-131.

Fujii, Tomohiro, \& Kensuke Takita. 2007. Wh-adverbials in-situ, their island-(in)sensitivity and the role of demonstratives in wh-in-situ licensing. Nanzan Linguistic 3(1). 107-126.

Fujii, Tomohiro, Kensuke Takita, Barry Chung-Yu Yang, \& Wei-Tien Dylan Tsai. 2014. Comparative remarks on wh-adverbials in situ in Japanese and Chinese. Japanese Syntax in Comparative Perspective. 181-205.

Huang, C.-T. James. 1982a. Logical relations in Chinese and the theory of grammar. Cambridge, MA: MIT dissertation.

Huang, C.-T. James. 1982b. Move $w h$ in a language without wh-movement. Linguistic Review 1(4). 369-416.

Jin, Dawei. 2016. The semantics-pragmatics interface and island constraints in Chinese. Buffalo, NY: University of Buffalo dissertation.

Ko, Heejeong. 2005. Syntax of why-in-situ: Merge into [Spec, CP] in the overt syntax. Natural Language \& Linguistic Theory 23(4). 867-916. https://doi.org/10.1007/s11049-0045923-3.

Ko, Heejeong. 2006. On the structural height of reason $w h$-adverbials: Acquisition and consequences. In N. C. Lisa Lai-Shen Cheng \& Norbert Corver (eds.), Wh-movement: Moving on. 319-349. Cambridge, MA: MIT Press.

Lin, Jo Wang. 1992. The syntax of zenmeyang 'how' and weishenme 'why' in Mandarin Chinese. Journal of East Asian Linguistics 1. 293-331. https://doi.org/10.1007/BF00130555.

Murphy, Andrew. 2017. Toward a unified theory of wh-in-situ and islands. Journal of East Asian Linguistics 26(2). 189-231. https://doi.org/10.1007/s10831-017-9155-z.

Ochi, Masao. 2014. Wh-adjuncts, left periphery, and wh-in-situ. In Y.-H. Audrey Li, Andrew 
Simpson and W.-T. Dylan Tsai (eds.), Chinese syntax in a cross-linguistic perspective, 401-428. New York: Oxford University Press.

Rizzi, Luigi. 1990. Relativized Minimality. Cambridge, MA: MIT Press.

Shlonsky, Ur, \& Gabriela Soare. 2011. Where's 'why'? Linguistic Inquiry 42. 651-669.

Stepanov, Arthur, \& Wei-Tien Dylan Tsai. 2008. Cartography and licensing of $w h$-adjuncts: a cross-linguistic perspective. Natural Language \& Linguistic Theory 26(3). 589-638.

Tsai, Wei-Tien Dylan. 1994a. On economizing the theory of A-bar dependencies. Cambridge, MA: MIT dissertation.

Tsai, Wei-Tien Dylan. 1994b. On nominal islands and LF extraction in Chinese. Natural Language and Linguistic Theory 12. 121-175. https://doi.org/10.1007/BF00992747.

Tsai, Wei-Tien Dylan. 2008. Left periphery and how-why alternations. Journal of East Asian Linguistics. 17(2). 83-115. https://doi.org/10.1007/s10831-008-9021-0.

Yeo, Seungju. 2019. On the -key toy-construction as implicit causatives. Studies in Linguistics 51. 49-68. 